\title{
PATTERN OF IMPACTED THIRD MOLARS AND THEIR ASSOCIATED RADIOGRAPHIC PATHOLOGICAL LESIONS IN MAKKAH REGION: A RETROSPECTIVE RADIOGRAPHIC SURVEY
}

\author{
Ali K. Barakat * and Reda.A.Nofal **
}

\begin{abstract}
Background: In recent centuries the wisdom tooth impaction of both jaws considered a public health problem, because lack of space to erupt normally or even to appear in the oral cavity, this sequela may be due to insufficient activity of the jaws over the centuries.

Aim of the Study: The purpose of this study was to determine the prevalence of impacted wisdom associated with pathologies in relation to angulation of impaction in an adult Saudi population in Mecca area,

Materials and Methods: This is a cross sectional study in which records of 4000 patient's panoramic radiographs between 2017 -2018 from OPG \& CEPH X-Ray Department. Umm AlQura University-Dental College and Hospital were reviewed. Finally, 411 out of 4000 patient's radiographs which showed impacted wisdom were selected. Data related to the type of impaction in both jaws and associated pathologies were then collected, tabulated and analyzed.
\end{abstract}

Results: Panoramic radiographs of 4000 patients aged 25-60 years were examined. A total of $411(10.27 \%)$ demonstrate the presence of at least one impacted third molar. The study demonstrates that the highest number of impactions related to mandibular arch followed by maxillary arch then the least common cases with impaction related to both jaws. For the angulation of the impacted third molars, the most common angulation was vertical folwed by mesioangular and distoangular angulations were the less common, while the least common angulation was Horizontal. The most angulated wisdom associated with pathologies was the mesioangular angulation followed by vertical then the least common pattern distoangular and horizontal. The other angulations were negligible. The most common radiographic features of lesions associated with the third molar were radiolucent lesions Followed by radiopaque lesions. And the least common lesions were mixed lesions.

Conclusion: The radiographic features of impacted wisdom angulation could be correlated to their pathologies among all cases in Makkah region.

KEYWORDS: Radiography, Panoramic, Impacted Wisdom, Prevalence, Pathology.

\footnotetext{
* Bachelor's Degree in Dental Medical and Surgery, Faculty of Dentistry, Umm Al Qura University, Saudi Arabia.

** Professor of Oral and Maxillofacial Surgery, Faculty of Dentistry, Umm Al Qura University, Saudi Arabia.
} 


\section{INTRODUCTION}

Impacted teeth are the teeth that fail to erupt into the oral cavity within the dental arch within the predicted time. ${ }^{(1)}$ There're several systemic and local factors that may lead to teeth impaction, the main local factors for teeth impaction are: adjacent teeth, dense overlying bone, excessive soft tissue, genetic abnormality prevents eruption and inadequate dental arch length and space. ${ }^{(2)}$

Durbeck 1943 mentioned five main theories for teeth impaction: Orthodontic theory explained the impaction because of jaws develop in downward and forward direction. Movement of teeth occurs in forward direction any abnormalities within these movements may cause an impaction. Phylogenic theory mentioned that over centuries and generations both jaws get smaller and leaving insufficient room for wisdom teeth. Mendelian theory heredity was most common cause. This may be an important etiological factor in the occurrence of impaction. Pathological theory mentioned that the chronic infections affecting an individual may bring the condensation of osseous tissue further preventing the growth and development of the jaws. Endocrinal theory was about any increase or decrease in growth hormone secretion may affect the size of the jaws. ${ }^{(3)}$

There're several studies described the tooth impaction as a frequent phenomenon. However, there was a difference in the prevalence of teeth impaction among different population and regions, as well as the distribution and prevalence variations of impacted teeth in different regions of the jaw. Definite age group, time of teeth eruption and radiographic criteria are some of the factors that affect the prevalence of teeth impaction. ${ }^{(4-7)}$

The most common teeth that fails to erupt into the oral cavity are the maxillary and mandibular third molars, followed by the maxillary canines and mandibular premolars. The third molars are the most frequently impacted tooth because they are the last teeth to erupt and the jaws have inadequate space for their normal eruption. ${ }^{(8)}$ In several studies they found that impacted mandibular wisdom is frequently more prevalent than impacted maxillary wisdom teeth. The prevalence of mesioangular impacted wisdom tooth was significantly higher than other angulations in the mandible while in the maxilla the vertical impaction was more frequent than another angulation. ${ }^{(9-13)}$

Wisdom tooth is the last tooth that appears in the oral cavity, many times this tooth have inadequate space for its complete eruption. There're so many pathological conditions associated with wisdom tooth retention. ${ }^{(14)}$

Adverse conditions arising from retained tooth such as: Pericoronitis and related infections, orthodontic problems, odontogenic cysts, odontogenic tumors, dental caries, periodontal disease and mandible fractures. ${ }^{(15,16)}$

Impaction classification was described by several methods, such as angulation and level of impaction such as: a classification was given by Pell \& Gregory (1933). This is based on the relationship between the impacted lower wisdom (3rd molar) tooth to the ramus of the mandible and the 2nd molar based on the space available distal to the 2 nd molar. Another wisdom impaction classification was described by Winter (1926) and classified the lower wisdom (3rd molar) impaction by the angle formed by the long axis of the impacted wisdom and the long axis of the tooth adjacent to it. For the upper wisdom (3rd molar) Archer (1975) and Kruger (1984) pioneered the angulation classification based on the radiographic position and angulation of the third molars. Different angulations of impaction were present: mesioangular, distoangular, horizontal, vertical, bucco-lingual version and inverted position. Impaction also classified according to the occlusal height, amount of distal bone covering the distal portion of tooth and the tooth overlying tissue (soft or hard tissues). ${ }^{(17-21)}$

Orthopantomograms (OPG) radiographs are a diagnostic aid to discover tooth impaction presence within the jaws, angulation of impaction, anatomical obstacles preventing the normal tooth eruption, amount of surrounding bone, relation to adjacent 
teeth, and vital structures. Therefore, an accurate evaluation results in a correct planning and treatment in this regard. ${ }^{(22)}$

Currently there's no data on the prevalence of impacted wisdom angulation in association with pathologies in Mecca city.

\section{Aim of the Study}

The aim of this study was to investigate the Prevalence of impacted wisdom angulation in association with radiographic signs of pathology in panoramic radiographs of Saudi population in Mecca area.

\section{MATERIALS AND METHODS}

A cross sectional study of Consecutive panoramic radiographs of the patients with impacted third molars who attended the Department of Oral and Maxillofacial Surgery was carried out. Radiographs were taken from (OPG \& CEPH. X-Ray Department). Umm Al-Qura University-Dental College and Hospital.

\section{Study sample}

Firstly, the records of 4000 patient's panoramic radiographs between (2017 -2018) were reviewed. Finally, 411 out of 4000 patient's radiographs which showed impacted wisdom were selected. The analysis of the type of impaction in both jaws and associated pathologies were then assessed.

\section{Patients selection}

Inclusion criteria: radiographic evidence of wisdom impaction within the age group of 25 to 60 years with at least one impacted wisdom. Exclusion criteria: inability to classify the impaction angle and if we can't examine the radiographs due to radiographic error.

\section{Angulation measurements}

The angulations of wisdom impaction were measured by the angle formed by the long axes of the impacted wisdom and the adjacent tooth according
Archer (1975) and Kruger (1984) classification for wisdom impaction. ${ }^{(23)}$

\section{Associated Pathologies}

Pathologies associated with impacted wisdom were observed on radiograph according to radiolucency: Radiolucent lesions considered when there is an increase in the pericoronal space of the dental follicle more than $3 \mathrm{~mm}$ around the impacted tooth. Radiopaque lesions considered when there were any radiopacity related to the impacted wisdom while the mixed lesions considered when both radiolucent and radiopaque appearance were associated with the impacted tooth. (Picture 1-3). ${ }^{(24)}$

\section{Ethical approval}

This study followed the protocol and ethics, it was approved by the Ethical Review Board of Umm Al-Qura University Dental College.

\section{Statistical Analysis}

All the collected data were coded, and tabulated. Statistical analysis was performed by Microsoft Office 2013 (Excel) and IBM SPSS Statistics for version 22. Descriptive analysis was performed using simple frequencies and percentage. Chi square test was performed to test the significance difference between the groups. P value of 0.05 was used as level of significance. (tables 1-3).

TABLE (1) Illustrate the $\mathrm{P}$ value for the statistical comparison between total impacted wisdom associated with the arches and angulated wisdom associated with pathologies.

\begin{tabular}{|c|c|c|c|}
\hline \multicolumn{4}{|c|}{ Chi-Square Tests } \\
\hline & Value & df & $\begin{array}{c}\text { Asymp. Sig. } \\
\text { (2-sided) }\end{array}$ \\
\hline Pearson Chi-Square & $1590.090^{\mathrm{a}}$ & 18 & .000 \\
\hline Likelihood Ratio & 1507.881 & 18 & .000 \\
\hline $\begin{array}{c}\text { Linear-by-Linear } \\
\text { Association }\end{array}$ & 518.668 & .000 & .000 \\
\hline N of Valid Cases & 878 & & \\
\hline
\end{tabular}

a. 7 cells (23.3\%) have expected count less than 5. The minimum expected count is $\mathbf{4 0 .}$ 
TABLE (2) Illustrate the $\mathrm{P}$ value for the statistical comparison between total impacted wisdom associated with the arches and the pathologies associated with the arches.

\begin{tabular}{|c|c|c|c|}
\hline \multicolumn{4}{|c|}{ Chi-Square Tests } \\
\hline & Value & df & $\begin{array}{c}\text { Asymp. Sig. } \\
\text { (2-sided) }\end{array}$ \\
\hline Pearson Chi-Square & $530.390^{\mathrm{a}}$ & 6 & .000 \\
\hline Likelihood Ratio & 718.168 & 6 & .000 \\
\hline $\begin{array}{c}\text { Linear-by-Linear } \\
\text { Association }\end{array}$ & 423.653 & 1 & .000 \\
\hline N of Valid Cases & 878 & & \\
\hline
\end{tabular}

a. 1 cells $(8.3 \%)$ have expected count less than 5 . The minimum expected count is 2.81

TABLE (3) Illustrate the $\mathrm{P}$ value of the statistical comparison between angulated wisdom associated with pathologies and the pathologies associated with the arches.

\begin{tabular}{|c|c|c|c|}
\hline \multicolumn{4}{|c|}{ Chi-Square Tests } \\
\hline & Value & df & $\begin{array}{c}\text { Asymp. Sig. } \\
\text { (2-sided) }\end{array}$ \\
\hline Likelihood Ratio & 1559.505 & 27 & .000 \\
\hline $\begin{array}{c}\text { Linear-by-Linear } \\
\text { Association }\end{array}$ & 722.534 & 1 & .000 \\
\hline N of Valid Cases & 878 & & \\
\hline
\end{tabular}

14 cells (35.0\%) have expected count less than 5. The minimum expected count is .13.

\section{RESULTS}

Panoramic radiographs of 4000 patients aged 25-60 years were examined. A total of $411(10.27 \%)$ demonstrate the presence of at least one impacted third molar. The study demonstrate that the total number of maxillary impacted wisdom teeth were $412(\% 47)$ and the mandibular impacted wisdom teeth were 378 (\%43) while the impacted wisdom in both jaws were 88 (\%10) (table 4). For the angulation of the impacted third molars, the most common angulation was vertical followed by mesioangular, and distoangular angulations were less common, but the least common angulation was horizontal.
Results were summarized in (figure 1). The most angulated wisdom associated with pathologies in relation to other angulations was the mesioangular (\%35.5) followed by vertical (\%31.4) then, distoangular (\%17.3) and horizontal (\%13.3) were the least common pattern, while the other angulations (\%2.5) were negligible (Table 5). Lesions were detected radiographically in $28(17.8 \%)$ maxillary third molars and $129(82.2 \%)$ mandibular third molars (Table $6)$. For the angulated wisdom in association with pathology within the same angulation $(23.9 \%)$ of horizontal cases were associated with pathologies followed by mesioangular $(21.3 \%)$ than distoangular $(16.5 \%)$ and the least common was vertical (14.8\%) and other angulations pattern were $(12.1 \%)$ (Table 7). The most common radiographic lesion of the third molar was radiolucent lesions followed by radiopaque lesions and the least common lesion was mixed lesions (Figure 2). The maxillary impacted wisdom associated with pathologies was $(6.3 \%)$ while the Mandibular impacted wisdom associated with pathologies $(29.7 \%)$ this finding in relation to the same arch pathologies (table 8 ).

TABLE (4) Demonstrate the impacted teeth in maxilla, mandible \& both arches.

\begin{tabular}{|c|c|}
\hline Area of the jaw & Number $(\%)$ \\
\hline Maxillary impaction & $378(43 \%)$ \\
\hline Mandibular impaction & $412(47 \%)$ \\
\hline both & $88(10 \%)$ \\
\hline Total & $878(100 \%)$ \\
\hline
\end{tabular}

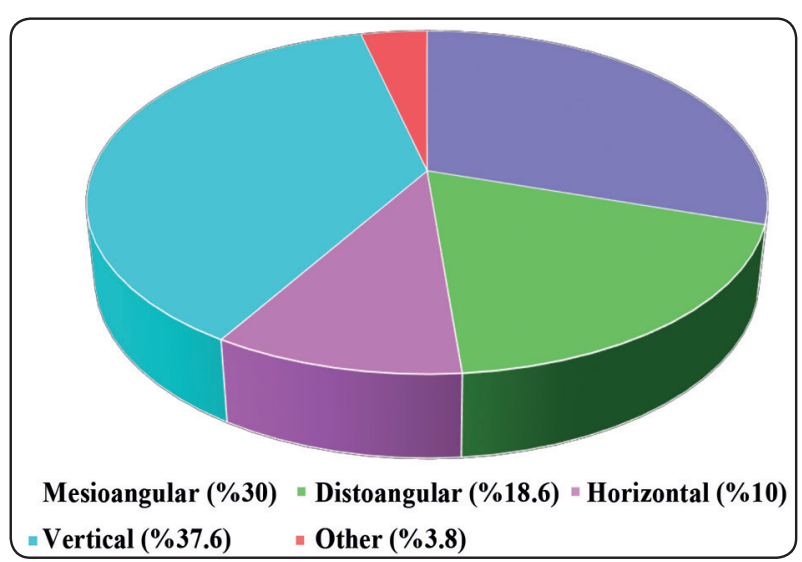

Fig. (1) Shows the Angulation percentage of impacted wisdom 
TABLE (5) Show the angular position in association with pathologies compared to other angulations.

\begin{tabular}{|c|c|c|}
\hline $\begin{array}{c}\text { Pattern of impac- } \\
\text { tion }\end{array}$ & $\begin{array}{c}\text { Associated with patholo- } \\
\text { gies Number }(\%)\end{array}$ & $\begin{array}{c}\text { Not associated with pa- } \\
\text { thologies Number (\%) }\end{array}$ \\
\hline Mesioangular & $56(35.5 \%)$ & $207(28.7 \%)$ \\
\hline Distoangular & $27(17.3 \%)$ & $137(19 \%)$ \\
\hline Vertical & $49(31.4 \%)$ & $281(39 \%)$ \\
\hline Horizontal & $21(13.3 \%)$ & $67(9.3 \%)$ \\
\hline Other & $4(2.5 \%)$ & $29(4 \%)$ \\
\hline Total & $157(100 \%)$ & $721(100 \%)$ \\
\hline
\end{tabular}

TABLE (6) Displays the impacted wisdom within the jaw in association with pathologies.

\begin{tabular}{|c|c|c|}
\hline Area of the Jaw & $\begin{array}{c}\text { Associated with pa- } \\
\text { thologies Number (\%) }\end{array}$ & $\begin{array}{c}\text { Not associated with pa- } \\
\text { thologies Number (\%) }\end{array}$ \\
\hline Maxillary impaction & $28(17.8 \%)$ & $415(57.5 \%)$ \\
\hline $\begin{array}{c}\text { Mandibular } \\
\text { impaction }\end{array}$ & $129(82.2 \%)$ & $306(42.5 \%)$ \\
\hline Total & $157(100 \%)$ & $721(100 \%)$ \\
\hline
\end{tabular}

TABLE (7) Show the impacted wisdom angulation associated and not associated with pathologies within the same angulation.

\begin{tabular}{|c|c|c|c|}
\hline $\begin{array}{c}\text { Pattern of impac- } \\
\text { tion }\end{array}$ & $\begin{array}{c}\text { Associated with } \\
\text { pathologies } \\
\text { Number (\%) }\end{array}$ & $\begin{array}{c}\text { Not associated } \\
\text { with pathologies } \\
\text { Number (\%) }\end{array}$ & Total \\
\hline Mesioangular & $56(21.3 \%)$ & $207(78.7 \%)$ & $\begin{array}{c}263 \\
(100 \%)\end{array}$ \\
\hline Distoangular & $27(16.5 \%)$ & $137(83.5 \%)$ & $\begin{array}{c}164 \\
(100 \%)\end{array}$ \\
\hline Vertical & $49(14.8 \%)$ & $281(85.2 \%)$ & $\begin{array}{c}330 \\
(100 \%)\end{array}$ \\
\hline Horizontal & $21(23.9 \%)$ & $67(76.1 \%)$ & $\begin{array}{c}88 \\
(100 \%)\end{array}$ \\
\hline Other & $4(12.1 \%)$ & $29(87.9 \%)$ & $\begin{array}{c}33 \\
(100 \%)\end{array}$ \\
\hline
\end{tabular}

TABLE (8) Display the impacted wisdom associated and not associated with pathologies within the jaw.

\begin{tabular}{|c|c|c|c|}
\hline $\begin{array}{c}\text { Area of the } \\
\text { Jaw }\end{array}$ & $\begin{array}{c}\text { Associated with } \\
\text { pathologies } \\
\text { Number }(\%)\end{array}$ & $\begin{array}{c}\text { Not associated with } \\
\text { pathologies Number } \\
(\%)\end{array}$ & Total \\
\hline $\begin{array}{c}\text { Maxillary } \\
\text { impaction }\end{array}$ & $28(6.3 \%)$ & $415(93.7 \%)$ & $\begin{array}{c}443 \\
(100 \%)\end{array}$ \\
\hline $\begin{array}{c}\text { Mandibular } \\
\text { impaction }\end{array}$ & $129(29.7 \%)$ & $306(70.3 \%)$ & $\begin{array}{c}435 \\
(100 \%)\end{array}$ \\
\hline
\end{tabular}

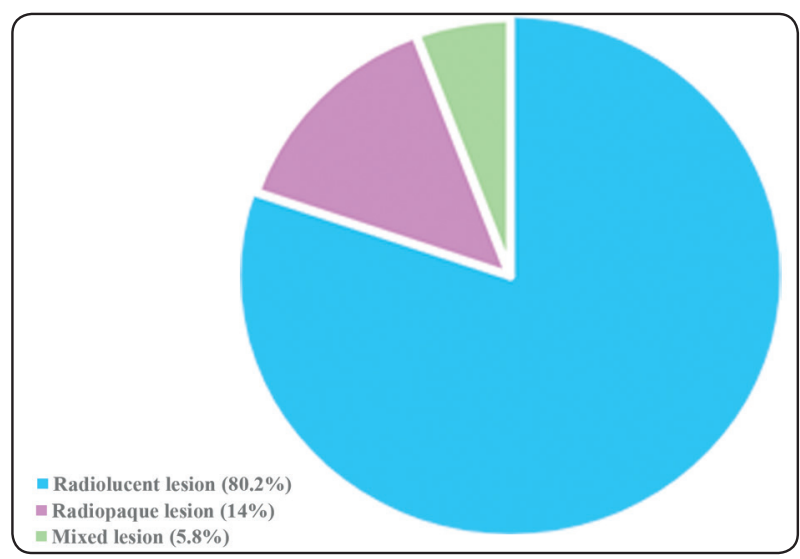

Fig. (2) Shows the percentage of the radiographic lesions.

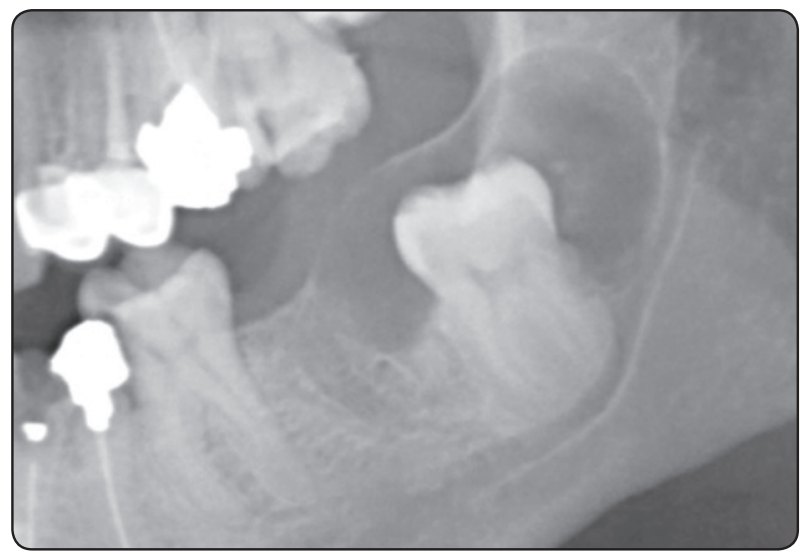

Picture (1) shows the impacted wisdom in association with radiolucent lesion. 


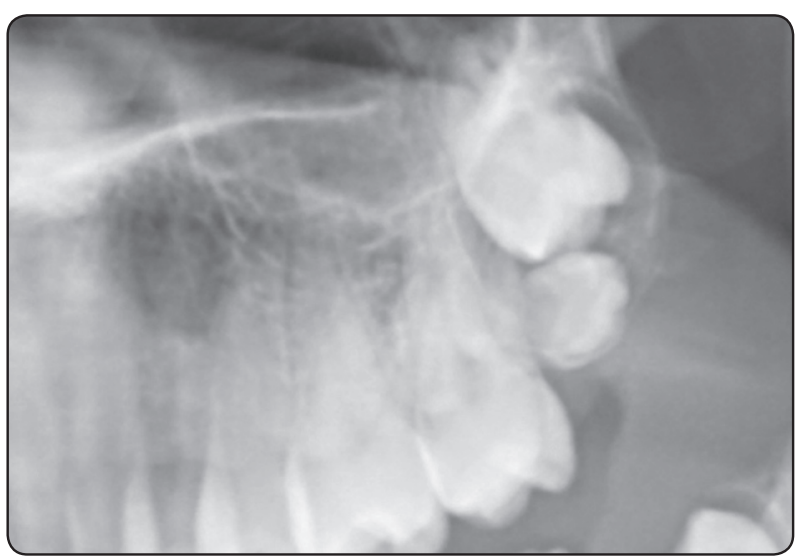

Picture (2) Shows the impacted wisdom in association with radiopaque lesion.

\section{DISCUSSION}

The prevalence of impacted third molar is variable in different populations, ranging from almost nil in Nigerians to $72 \%$ in the Swedish. ${ }^{(25)}$ in this study radiographic evaluation done with panoramic radiographs. The impacted third molars were classified radiographically according to the angulation impaction pattern, as done by Şimşek- Kaya et al. (26) Winter's classifications was used on the panoramic radiograph in this study as they were simple, practical, and easy to apply. In our study vertical angulation for impacted 3rd molars (37.6\%) were most common, whereas mesioangular $(30 \%)$ angulation was the next most common finding. The result was in accordance with that found by Hassan A, ${ }^{(10)}$ Alsehimy M. ${ }^{(11)}$ and Labeed et al., ${ }^{(27)}$ in the other hand Dogan et al., ${ }^{(28)}$ Bansal et al., ${ }^{(29)}$ and Ramamurthy et al., ${ }^{(30)}$ found that mesioangular pattern for impacted 3rd molars was most common, whereas vertical angulation was their next most common finding. however, the frequency of pathology was highest in the mesioangular position $(35.5 \%)$, followed by vertical $(31.4 \%)$, distoangular (17.3\%) and the least common was horizontal (13.3\%). This may be explained by the following: The occlusal surface of a mesioangular impacted tooth slope upward and mesially push the adjacent tooth by its eruption force and the amount of soft tissue covering a mesioangular impacted third molar is less and allow for the oral flu-

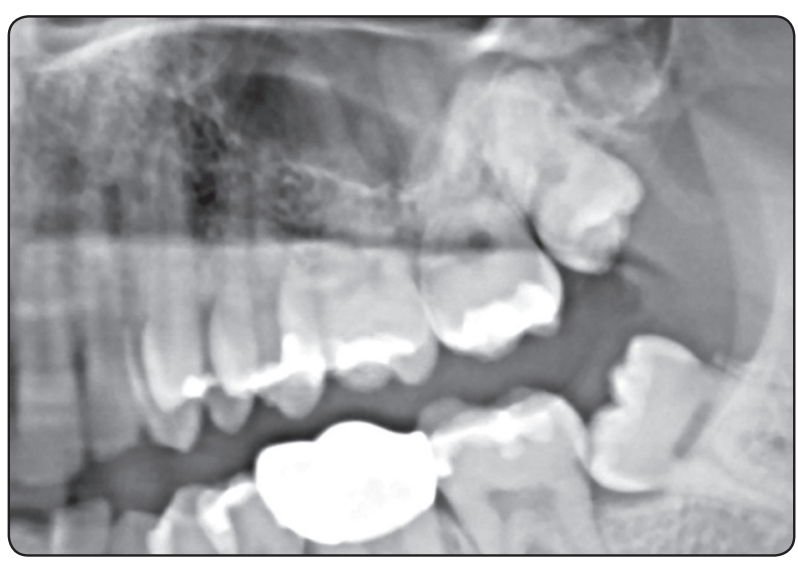

Picture (3) Shows the impacted wisdom in association with mixed lesion.

ids to leaked into the follicle than that with vertical, distoangular and horizontal impaction. In our study we found that mandibular impacted wisdom with associated pathologies (82.2\%) is more than maxillary impacted wisdom associated with pathologies (17.8) this result was in accordance with Jung Y. ${ }^{(31)}$ and this may be due to bone structure of the mandible tend to localize the spread of infection and the pathologies in the other hand maxillary bone nature tend to spread the lesion. regarding the nature of the pathologies we discovered that radiolucent lesions $(80.2 \%)$ tend to be more compared to radiopaque lesions (14\%) and mixed lesions (5.8\%) was the least lesions.

\section{CONCLUSION}

Incidence of tooth impaction was higher in the mandible compared to maxilla. Highest incidence of impacted wisdom angulation was vertical impaction type followed by mesioangular then distoangular and the least common was horizontal impaction another impaction such as buccolingual impaction, inverted and ectopic impaction was negligible. The radiographical features of impacted third molar angulation pattern may be correlated to their pathological complications. In this study the mandibular impaction was associated more frequently with radiographic pathologies than maxillary impaction. The predominant angulation pattern that was associated 
with radiographic abnormalities was mesioangular impaction type followed by vertical impaction then distoangular and the least common was horizontal impaction. (80.2\%) of cases had radiolucent lesion in association with impacted wisdom and (14\%) of cases showed radiopaque lesion and for the mixed lesion $(5.8 \%)$.

\section{REFERENCES}

1. Suri L, Gagari E, Vastardis H. Delayed tooth eruption: Pathogenesis, diagnosis, and treatment. A literature reviews. J Am Orthod Dentofacial Orthop. 2004;126(4): 432-45.

2. Frost, Hersh, Levin. Management of impacted teeth. Fonseca Oral and Maxillofacial Surgery. 2000, Volume I. Philadelphia: Saunders;.245-80.

3. Nodine AM: Impacted and Aberrant teeth, their history, causes and treatment, J Dental items intrest 1947; 69(11): 894-910.

4. Hou R, Kong L, Ao J, Liu G, Zhou H, Qin R, Hu K. Investigation of impacted permanent teeth except the third molar in Chinese patients through an X-ray study. J Oral Maxillofac Surg 2010;68(4):762-767.

5. Quek SL, Tay CK, Tay KH, Toh SL, Lim KC. Pattern of third molar impaction in a Singapore Chinese population: A retrospective radiographic survey. Int J Oral Maxillofac Surg. 2003;32(5):548-552.

6. Kruger E, Thomson WM, Konthasinghe P. Third molar outcomes from age 18 to 26: findings from a populationbased New Zealand longitudinal study. J Oral Surg Oral Med Oral Pathol Oral Radiol Endod. 2001;92(2):150-155.

7. Hattab FN, Fahmy MS, Rawashedeh MA. Impaction status of third molars in Jordanian students. J Oral Surg Oral Med Oral Pathol Radiol Endod. 1995;79(1):24-29

8. Dimitroulis G. A Synopsis of Minor Oral Surgery. Oxford university press: 1997 . Chapter 6, pp 48-57.

9. Hasan L, Ahmad F, Abdullah E. Impacted wisdom teeth, prevalence, pattern of impaction, complications and indication for extraction: A pilot clinic study in Iraqi population. J Tikrit for Dental Sciences.2016;4(1):50- 62.

10. Hasan A. Pattern of third molar impaction in a Saudi population. Clinical, Cosmetic and Investigational Dentistry. 2010:2010(2):109-113.
11. Jan A, Alsehaimy M, Mokhtar H, Jadu F. Prevalence of impacted third molars in Jeddah, Saudi Arabia: a retrospective study. Journal of American Science 2014;10(10):1-4.

12. Syed K, Kota Z, Ibrahim M. Prevalence of Impacted Molar Teeth among Saudi Population in Asir Region, Saudi Arabia - A Retrospective Study of 3 Years. J International Oral Health. 2013;5(1):43-47.

13. Hashemipour M, Arashlow M, Hanzaei F. Incidence of impacted mandibular and maxillary third molars: a radiographic study in a Southeast Iran population. J Med Oral Patol Oral Cir Bucal. 2013;18(1):140-145.

14. Gonzalez SM, Spalding PM, Payne JB, Giannini PJ. A dentigerous cyst associated with bilaterally impacted mandibular canines in a girl: a case report. J Med Case Rep $201123 ; 5$ : 230-234.

15. Planinić D, Bodina I, Perić B. Prevalence of odontogenic keratocysts associated with impacted third molars. J Coll Antropol. 2010;34(1):s221-224.

16. Falaki F, Delavarian Z, Salehinejad J, Sagha S. Squamous cell carcinoma arising from an odontogenic keratocyst: a case report. Med Oral Patol Oral Cir Bucal 2009;14(4): 171-174.

17. Björk A, Jensen E, Palling M. Mandibular growth and third molar impaction. J Acta Odont Scand. 1956; 14(3): 231-272.

18. Winter, GB. Impacted Mandibular Third Molar. St Louis, American Medical Book Co., 1926.

19. Pell G, Gregory B. Impacted mandibular third molars: classification and modified techniques for removal. J Dent Digest 1933;39(9):330- 338 .

20. Archer, WH. Oral \& Maxillofacial Surgery, 5th Edition. Saunders, Philadelphia, PA. 1975. 21- Kruger, GO. Oral \& Maxillofacial Surgery, 6th Edition. Mosby, St Louis, Mo. 1984.

21. Peterson LJ. Principles of management of impacted teeth. In: Peterson LJ, Ellis E III, Hupp JR, Tucker MR, eds. Contemporary Oral and Maxillofacial Surgery, 3rd Edition. Philadelphia: CV Mosby, 1998.

22. Molander B, Ahlqwist M, Grondahl H-G, Hollender L. Agreement between panoramic and intra oral radiography in the assessment of marginal bone height. J Dent MaxillofacRadiol. 1991;20(3):155-160. 
23. Juodzbalys G, Daugela P. Mandibular Third Molar Impaction: Review of Literature and a Proposal of a Classification. J Oral Maxillofac Res. 2013;4(2):1-12.

24. Mortazavi H, Baharvand M. Jaw lesions associated with impacted tooth: A radiographic diagnostic guide. J Imaging Sci Den. 2016; 46(3):147-15.

25. Kurchid N, Shihab O. Pattern of mandibular third molar impaction in patients attended the Hawler College of Dentistry: A retrospective radiographic study. J Zanco Med Sci. 2010;14(1):1-4.

26. Göksel Şimşek-Kaya, Mehmet Melih-Ömezli, Günay Yapıcı, Ertunç Dayı, Ümit Ertaş. Prevalence of impacted premolars in a Turkish population and considerations for surgical treatment: Med Oral Patol Oral Cir Bucal. 2011;16(6):781-786.

27. Labeed H, Ahmad F, Abdullah E. Impacted wisdom teeth, prevalence, pattern of impaction, complications and indi- cation for extraction: A pilot clinic study in Iraqi population. J Tikrit for Dental Sciences. 2016;4(1)50- 62.

28. Doğan N, Orhan K, Günaydin Y, Köymen R, Okçu K, Uçok O. Unerupted mandibular third molars: Symptoms, associated pathologies, and indications for removal in a Turkish population. Quintessence Int 2007;38(8):497-505.

29. Bansal S, Rajesh S. Is it wisdom to remove a wisdom tooth? -Extraction versus nonextraction management of impacted tooth. J Indian Dent Sci 2010;2(3):4-6.

30. Ramamurthy A, Pradha J, Jeeva S, Jeddy N, Sunitha J, Kumar S. Prevalence of mandibular third molar impaction and agenesis: A radiographic South Indian study. J Indian Acad Oral Med Radiol 2012;24(3):173-176.

31. Jung Y, Cho B. Prevalence of missing and impacted third molars in adults aged 25 years and above. J Imaging Science in Dentistry 2013;43(4):219-225. 